\title{
Spiral ganglion cell degeneration-induced deafness as a consequence of reduced GATA factor activity
}

\author{
Tomofumi Hoshino $^{1,2}$ ｜ Tsumoru Terunuma ${ }^{1,3}$ | Jun Takai ${ }^{4}$ | Satoshi Uemura $^{4}$ | \\ Yasuhiro Nakamura $^{5}$ | Michito Hamada ${ }^{3}$ | Satoru Takahashi ${ }^{3}$ | Masayuki Yamamoto ${ }^{2}$ | \\ James Douglas Engel $^{6}$ | Takashi Moriguchi ${ }^{4}$ (D)
}

${ }^{1}$ Department of Otolaryngology, Faculty of Medicine, University of Tsukuba, Tsukuba, Japan

${ }^{2}$ Department of Medical

Biochemistry, Tohoku University Graduate

School of Medicine, Sendai, Japan

${ }^{3}$ Department of Anatomy and Embryology, Faculty of Medicine, University of

Tsukuba, Tsukuba, Japan

${ }^{4}$ Division of Medical Biochemistry, Tohoku Medical Pharmaceutical University, Sendai, Japan

${ }^{5}$ Division of Pathology, Tohoku Medical Pharmaceutical University, Sendai, Japan

${ }^{6}$ Cell and Developmental

Biology, University of Michigan, Ann

Arbor, Michigan

\section{Correspondence}

Takashi Moriguchi, Division of

Medical Biochemistry, Tohoku Medical

Pharmaceutical University, Sendai, Japan.

Email: moriguchi@tohoku-mpu.ac.jp

\section{Present address}

Tomofumi Hoshino, Department of Otorhinolaryngology, Kasumigaura Medical Center, National Hospital Organization,

Tsuchiura, Japan

\section{Funding information}

Grant-in-Aid for Scientific Research (B)

and on Innovative Areas, Grant/Award

Number: 16H05147 and 18H05041;

Kobayashi Foundation for Cancer Research

Communicated by: Shunsuke Ishii

\begin{abstract}
Zinc-finger transcription factors GATA2 and GATA3 are both expressed in the developing inner ear, although their overlapping versus distinct activities in adult definitive inner ear are not well understood. We show here that GATA2 and GATA3 are co-expressed in cochlear spiral ganglion cells and redundantly function in the maintenance of spiral ganglion cells and auditory neural circuitry. Notably, Gata2 and Gata3 compound heterozygous mutant mice had a diminished number of spiral ganglion cells due to enhanced apoptosis, which resulted in progressive hearing loss. The decrease in spiral ganglion cellularity was associated with lowered expression of neurotrophin receptor TrkC that is an essential factor for spiral ganglion cell survival. We further show that Gata2 null mutants that additionally bear a Gata2 YAC (yeast artificial chromosome) that counteracts the lethal hematopoietic deficiency due to complete Gata2 loss nonetheless failed to complement the deficiency in neonatal spiral ganglion neurons. Furthermore, cochlea-specific Gata2 deletion mice also had fewer spiral ganglion cells and resultant hearing impairment. These results show that GATA2 and GATA3 redundantly function to maintain spiral ganglion cells and hearing. We propose possible mechanisms underlying hearing loss in human GATA2- or GATA3-related genetic disorders.
\end{abstract}

\section{K E Y W O R D S}

Gata2, inner ear, spiral ganglion, yeast artificial chromosome (YAC) 


\section{1 | INTRODUCTION}

The mammalian inner ear is a complex and delicate sensory organ, consisting of cochlea, vestibulum and semicircular canals (SC; Whitfield, 2015). Auditory sensation begins in the cochlea of the inner ear; acoustic information is generated by inner ear hair cells of the organ of Corti and reaches spiral ganglion cells within the cochlea. The spiral ganglion cells are bipolar neurons that receive auditory information from the hair cells and transmit that information to the auditory center in the brain (Rubel \& Fritzsch, 2002).

Development of the cochlea begins as an ectodermal thickening known as the otic placode in the lateral rhombencephalon, which invaginates to form a rudimentary structure called the otic vesicle. Subsequently, the ventral part of the otic vesicle gives rise to the cochlea at embryonic day (e) 9.5. These developmental processes require intrinsic and extrinsic factors that regulate proliferation and differentiation of the otic vesicle to form the mature inner ear structure (Barald \& Kelley, 2004). A number of transcriptional regulators have been identified that play a role in development of the inner ear (Whitfield, 2015). Among them are GATA family of transcription factors, which all contain two $\mathrm{C}_{4}$ zinc fingers that serve as its DNA-binding domain and recognize the cognate consensus motif (A/T)GATA(A/G) (Ko \& Engel, 1993; Yamamoto et al., 1990). The zinc-finger domain of the GATA factors is conserved among the six members $($ Gatal $\sim 6)$ that constitute this multigene family. GATA2 and GATA3 are the only family members expressed in the developing inner ear (George et al., 1994; Haugas, Lillevli, Hakanen, \& Salminen, 2010; Lakshmanan, Lieuw, Grosveld, \& Engel, 1998; Lakshmanan et al., 1999; Lieuw, Li, Zhou, Grosveld, \& Engel, 1997; Lillevali, Matilainen, Karis, \& Salminen, 2004; Lim et al., 2012; Moriguchi et al., 2006). GATA3 is initially expressed in the otic placode at e8.0, and subsequently, GATA2 expression follows in the otic vesicle at e9.5 (Lawoko-Kerali, Rivolta, \& Holley, 2002; Lillevali et al., 2004). Thus, GATA2 and GATA3 expression overlaps in the otic vesicle in early-stage embryos.

A series of studies have elucidated a number of the developmental roles played by GATA3 in the inner ear (Duncan, Lim, Engel, \& Fritzsch, 2011; Lillevali et al., 2004; Lim et al., 2000; Moriguchi et al., 2018, 2006; Pandolfi et al., 1995; van der Wees et al., 2004). In Gata3 null embryos, inner ear development is arrested, whereas only a rudimentary otic vesicle is formed (Duncan et al., 2011; Karis et al., 2001; Lim et al., 2000; Moriguchi et al., 2006). Recently, we identified inner ear-specific regulatory sequences lying $571 \mathrm{~kb} \mathrm{3}^{\prime}$ to the Gata3 gene and designated that as the otic vesicle enhancer (OVE) (Moriguchi et al., 2018). When OVE-driven Cre recombinase transgenic mice were crossed with homozygous Gata3-floxed mutants, the Gata3 gene was specifically deleted in otic vesicle-derived inner ear tissues, and the resultant Gata3 conditionally deficient mice showed significant developmental defects in the inner ear (Moriguchi et al., 2018). Interestingly, molecular and clinical evidence has shown that haploinsufficiency in GATA3 leads to a dominantly inherited condition known as HDR syndrome, which is associated with the clinical triad of hypoparathyroidism, neural sensory deafness and renal defects (Van Esch et al., 2000). Thus, the evidence from mice and humans underscores a prominent role for GATA3 in specifying normal inner ear development.

GATA2 plays a crucial role in diverse developmental programs including the hematopoietic, neural and urogenital systems (Ainoya et al., 2012; Craven et al., 2004; Hoshino et al., 2008; Khandekar et al., 2007; Khandekar, Suzuki, Lewton, Yamamoto, \& Engel, 2004; Lim et al., 2012; Minegishi et al., 2003; Nozawa et al., 2009; Tsai et al., 1994; Zhou et al., 1998; Zhou, Yamamoto, \& Engel, 2000). Indeed, Gata2 homozygous null mutant embryos die by e10.5 from a lethal hematopoietic defect (Suzuki et al., 2006; Tsai et al., 1994). Haploid deficiency in human GATA2 leads to the clinical manifestation of Emberger syndrome, which presents as lymphedema, myelodysplasia or other hematopoietic disorders, including acute myeloid leukemia (Kazenwadel et al., 2012; Ostergaard et al., 2011). Notably, a subsequent clinical report showed that more than $75 \%$ of Emberger syndrome patients had accompanying sensorineural hearing loss, suggesting that GATA2 also participates in the program for human inner ear development (Spinner et al., 2014). However, the underlying etiological mechanism for deafness that accompanies GATA2 haploinsufficiency is obscure, largely because the early embryonic lethality of Gata2-deficient mice has hampered deeper mechanistic analysis of definitive inner ear development.

In the present study, we addressed the precise expression pattern of GATA2 and GATA 3 in the developing inner ear and examined their possibly overlapping functions in the maintenance of hearing ability. We found that GATA2 and GATA3 expression colocalized in the spiral ganglion cells of the cochlea. Gata2 and Gata3 compound heterozygous mutant mice showed a diminished number of spiral ganglion cells accompanying a severe hearing loss, whereas either Gata2 or Gata3 single heterozygous mutant mice showed only marginal changes in the spiral ganglion. We show that homozygous Gata2 null mutants crossed with Gata2 YAC transgenic mice (which circumvent the Gata2 ${ }^{-/-}$embryonic lethal hematopoietic deficiency) also have significantly fewer spiral ganglion cells in the neonatal stage. Finally, cochleaspecific Gata2-conditional deletion mice show a similar decrease in the number of spiral ganglion cells and subsequent hearing impairment. These results for the first time show that both GATA2 and GATA3 play redundant roles in the maintenance of spiral ganglion cells and auditory function. 


\section{2 | RESULTS}

\section{1 | GATA2 and GATA3 are co-expressed in the spiral ganglion cells of the cochlea}

To examine the detailed expression pattern of GATA2 and GATA3 during inner ear development, we used Gata2 GFP knock-in $\left(\right.$ Gata2 $\left.^{\mathrm{G} /+}\right)$ and Gata3 LacZ knock-in $\left(\right.$ Gata3 $\left.^{\mathrm{Z} /+}\right)$ mice, in which GFP or $L a c Z$ reporter genes were inserted at the translational initiation site of the Gata2 and Gata3 genes, respectively (Hendriks et al., 1999; Suzuki et al., 2006). In the Gata $3^{\mathrm{Z} /+}$ embryos, $L a c Z$ expression was observed in the otic vesicle at e10.5 and continually detected through e12.5 (arrowheads in Figure 1A,B). In the dissected inner ear tissue of e14.5 $\mathrm{Gata}^{\mathrm{Z} /+}$ embryos, LacZ expression was observed in the three main regions of the inner ear [i.e., in the cochlea (Co), vestibules (Ve) and SC; Figure 1C]. In the $\operatorname{Gata2}^{\mathrm{G} /+}$
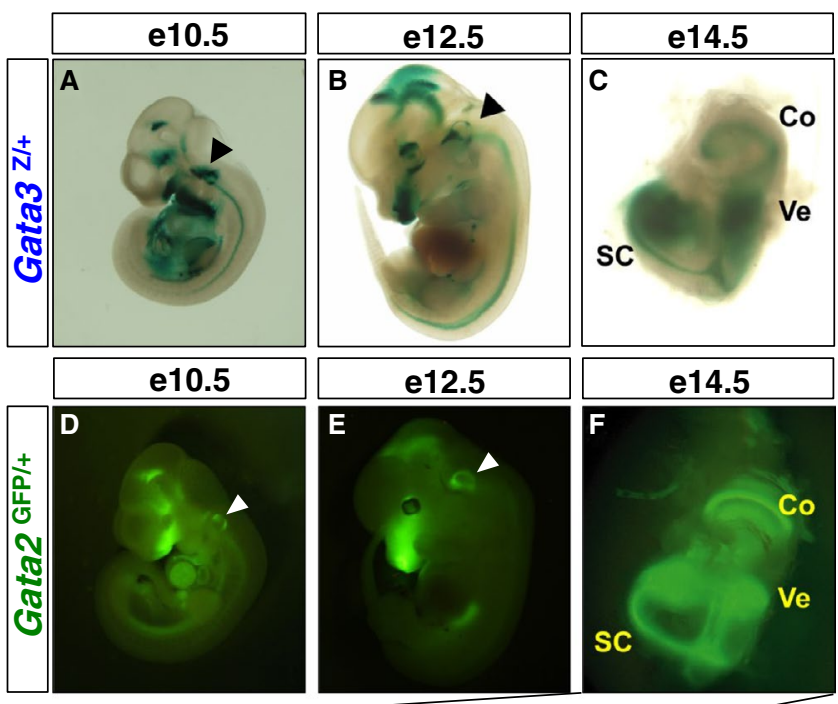

Axial sections of cochlea (e14.5)
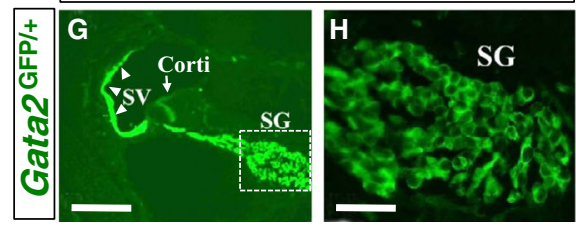

F I G URE 1 Expression of GATA2 and GATA3 during the inner ear development. (A and B) Gata3 ${ }^{\mathrm{Z} /+}$ embryos show LacZ expression in the otic vesicle (arrowheads) at e10.5 and e12.5 dpc. (C) LacZ expression was detected in the cochlea (Co), vestibules (Ve) and semicircular canals (SC) in the dissected inner ear tissue of e14.5 Gata $^{\mathrm{Z} /+}$ embryo. (D-F) GFP fluorescence was detected in the otic vesicle (arrowhead) of Gata $^{\mathrm{G} /+}$ embryos at e10.5 and e12.5. Inner ear tissue of the e14.5 Gata $^{\mathrm{G} /+}$ embryos showed GFP fluorescence in the cochlea, vestibule and SC. (G) An axial section of the cochlea of an e14.5 Gata $^{\mathrm{G} /+}$ embryo showed robust GFP expression in the spiral ganglion (SG, dotted rectangle) and stria vascularis (SV, arrowheads), whereas organ of Corti (arrow) showed only weak GFP fluorescence. (H) Higher magnification of the spiral ganglion showed a collection of GFP-positive cells. Scale bars: $40 \mu \mathrm{m}(\mathrm{G}), 10 \mu \mathrm{m}(\mathrm{H})$ embryos, GFP expression was distributed in a similar pattern to $L a c Z$ expression in the Gata $^{\mathrm{Z} /+}$ embryos. Robust GFP expression was detected in the otic vesicle of Gata2 $^{\mathrm{G} /+}$ embryos at e10.5 and e12.5 stages (white arrowheads in Figure 1D,E). In the e14.5 embryos, GFP expression was detected in the cochlea, vestibules and semicircular canal similarly to the Gata $^{\mathrm{Z} /+}$ embryos (Figure 1F). Axial sections of the e14.5 cochlea showed robust GFP fluorescence specifically in the spiral ganglion cells and endothelial cells in the stria vascularis, whereas hair cells in the organ of Corti showed only weak GFP fluorescence (Figure 1G,H).

To histologically assess the expression pattern of Gata2 and Gata3 in the cochlea, we crossbred the Gata2 ${ }^{\mathrm{G} /+}$ with Gata $^{\mathrm{Z} /+}$ mice and generated Gata $2^{\mathrm{G} /+}::$ Gata $^{\mathrm{Z} /+}$ compound heterozygous mutant mice. Thereafter, we examined the GFP and LacZ expression by anti-GFP immunohistochemistry and $\mathrm{X}$-gal staining in the transverse section of the cochlear duct at postnatal day 3 (P3). We found that GFP and LacZ were both robustly expressed in the spiral ganglion and organ of Corti (arrows and arrowheads in Figure 2A,D). Detailed analysis at higher magnification showed that the GFP and $\mathrm{LacZ}$ expression highly colocalized in the spiral ganglion cells in adjacent serial sections (arrowheads in Figure 2B,E). Double staining for GFP and $L a c Z$ in the same sections clearly

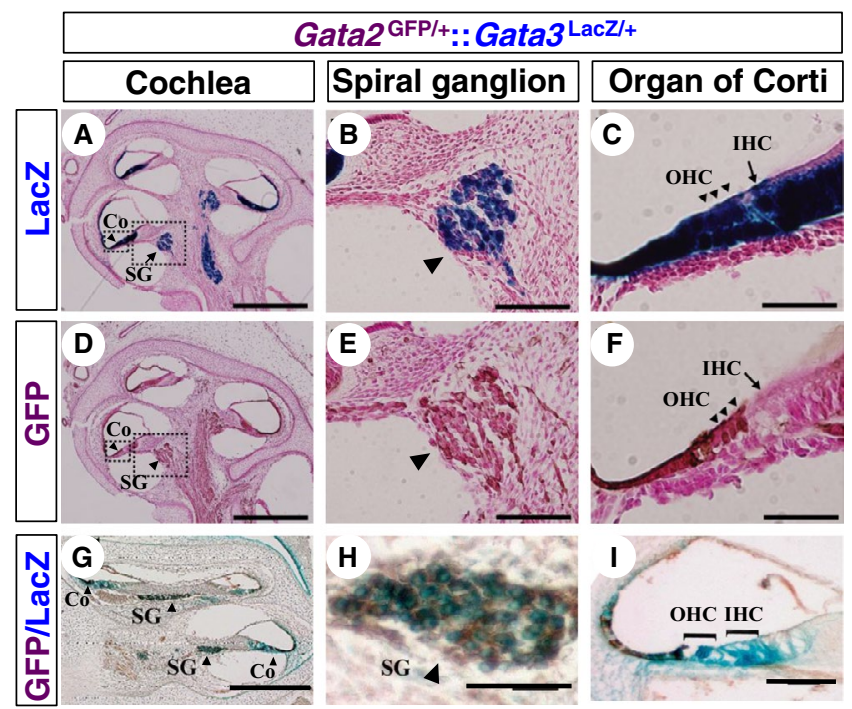

F IG URE 2 GATA2 and GATA3 are co-expressed in the spiral ganglion cells in the cochlea. In the cochlea of postnatal day 3 (P3) Gata2 $^{\mathrm{G} /+}:$ :Gata3 ${ }^{\mathrm{Z} /+}$ mice, GFP immunoreactivity (brown) and X-galstaining signals (blue) were detected in the spiral ganglion (SG) and organ of Corti (Co) (A, D and G). At higher magnification, the GFP and $L a c Z$ expression was colocalized in the vast majority of the spiral ganglion cells (arrowheads in B, E and H). (C, F and I) In the organ of Corti, robust $\mathrm{LacZ}$ expression was detected in both outer hair cells (OHC) and inner hair cells (IHC) (C), whereas modest GFP expression was detected only in the OHC. Scale bars: (A) and (D), $500 \mu \mathrm{m}$. (B) and (E), $200 \mu \mathrm{m}$. (C) and (F), $100 \mu \mathrm{m}$. (G) $200 \mu \mathrm{m}$. (H) $20 \mu \mathrm{m}$. (I) $40 \mu \mathrm{m}$ 
A

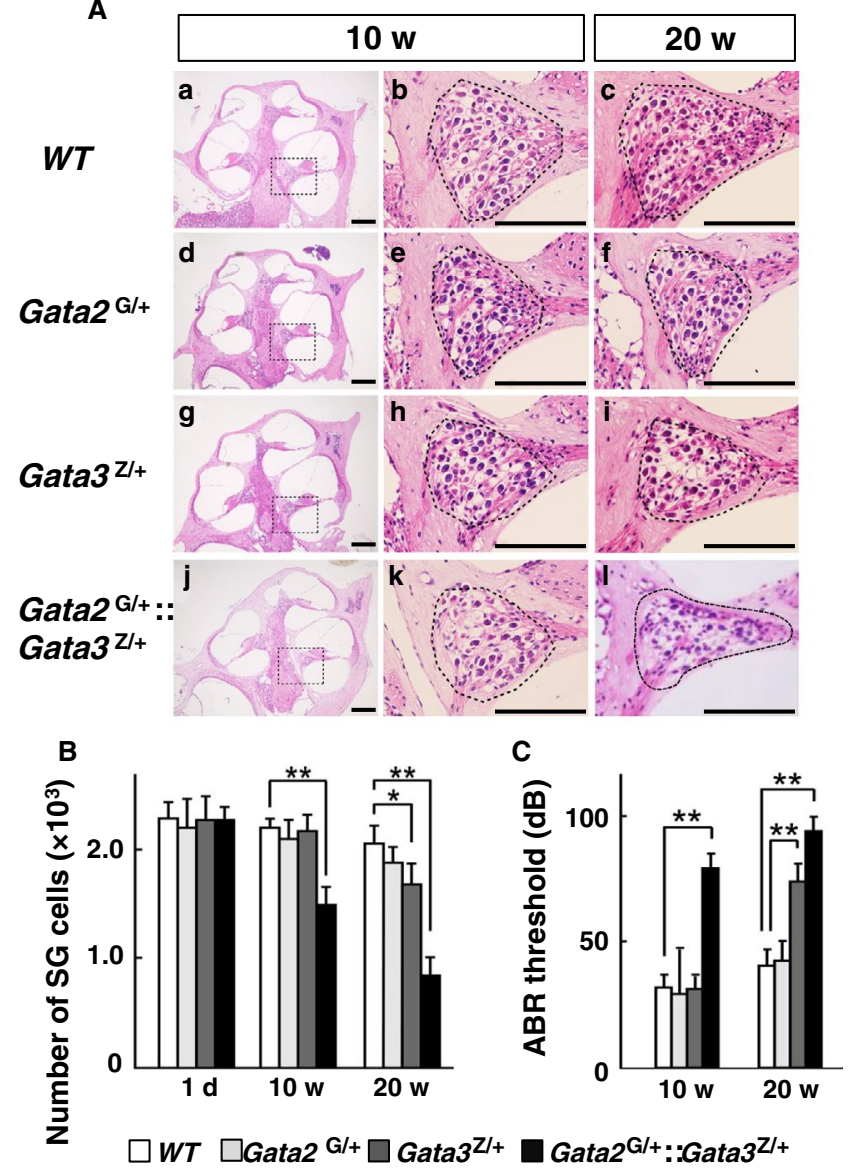

F I G U R E 3 Gata $2^{\mathrm{G} /+}::$ Gata $^{\mathrm{Z} /+}$ compound heterozygous mutant mice show progressive spiral ganglion cell loss and hearing impairment with age. (A) Axial sections of the cochlea in each genotype of mice show comparable gross architecture of the cochlear canal at 10 weeks of age (a, d, g and j). Gata $2^{\mathrm{G} /+}::$ Gata $^{\mathrm{Z} /+}$ mice showed a progressively diminished number of spiral ganglion cells at 10 and 20 weeks of age ( $k$ and 1$)$ in comparison with the age-matched wild-type control (b and c). Gata $3^{\mathrm{Z} /+}$ heterozygous mutant mice had a modest reduction in the spiral ganglion cell population at 20 weeks of age (i). Gata2 $2^{\mathrm{G} /+}$ (10 weeks and 20 weeks) and Gata $^{\mathrm{Z} /+}$ (10 weeks) mice appeared to have normal cellularity in the spiral ganglion (e, $\mathrm{f}$ and h). Scale bars: $200 \mu \mathrm{m}$. (B) Quantitative analyses of the number of residual spiral ganglion cells per cochlea at postnatal day 1 or after 10 weeks or 20 weeks of age. Gata $2^{\mathrm{G} /+}::$ Gata3 $^{\mathrm{Z} /+}$ mice had a progressive decrease in the spiral ganglion cell population at 10 and 20 weeks of age. Gata $^{\mathrm{Z} /+}$ heterozygous mutant mice showed a modest decrease in spiral ganglion cell number at 20 weeks of age. (C) Clickevoked ABR thresholds of each genotype of mice at 10 and 20 weeks of age. ABR thresholds of Gata $^{\mathrm{G} /+}::$ Gata $^{\mathrm{Z} /+}$ mice at 10 weeks of age were significantly more elevated than those in the age-matched wild-type mice. The age-matched ata $^{\mathrm{G} /+}$ or Gata $^{\mathrm{Z} /+}$ heterozygous mutants showed normal ABR threshold at 10 weeks of age. ABR thresholds of Gata $^{\mathrm{G} /+}::$ Gata $^{\mathrm{Z} /+}$ mice were even more elevated in the 20-week-old animals. Gata3 ${ }^{\mathrm{Z} /+}$ heterozygous mutant mice also showed increased ABR thresholds at 20 weeks of age. Data are presented as mean $\pm S D$. The statistical significance of differences are indicated $\left({ }^{*} p<0.05,{ }^{*} p<<0.001\right.$; Student's $t$ test). More than five mice in each group were subjected to statistical analysis showed colocalization of the GFP and X-gal signals in the spiral ganglion (Figure 2G,H). In the organ of Corti, the LacZ (i.e., Gata3 expression) was detected both in the outer and inner hair cells (Figure 2C,I). In contrast, GFP (i.e., Gata2 expression) was modestly expressed, and only in the outer hair cells (Figure 2F,I). Given the highly overlapping expression of GATA2 and GATA3 in the spiral ganglion cells, we anticipated that GATA2 and GATA3 might contribute to the development and maintenance of spiral ganglion cells in a partially redundant manner.

\section{2 | Diminished spiral ganglion cell numbers in Gata $^{\mathrm{G} /+}::$ Gata3 $^{\mathrm{Z} /+}$ compound mutant mice}

To address the possible functional contributions of GATA2 and GATA3 in the spiral ganglion cells, we first conducted histological analyses by hematoxylin and eosin (HE) examination of Gata $^{\mathrm{G} /+}::$ Gata $^{\mathrm{Z} /+}$ compound heterozygous cochlear sections. We found that the Gata2 ${ }^{\mathrm{G} /+}::$ Gata $^{\mathrm{Z} /+}$ mice showed atrophic changes in the spiral ganglion with decreased cellularity 10 weeks postnatally in comparison with age-matched wild-type mice (compare Figures 3 A-b to A-k). Quantitative analysis clearly showed that the number of remaining spiral ganglion cells in the Gata $^{\mathrm{G} /+}::$ Gata $^{\mathrm{Z} /+}$ mice was significantly fewer than that of age-matched wild-type mice at 10 weeks of age (Figure 3B). Individual Gata ${ }^{\mathrm{G} / 4}$ or Gata $^{\mathrm{Z} /+}$ heterozygous mutant mice did not show a similar decrease in spiral ganglion cells at the same age (Figure 3Ae, 3A-h and 3B). Decreased cellularity in spiral ganglia was further exaggerated in 20 -week-old Gata $^{\mathrm{G} /+}::$ Gata $^{\mathrm{Z} /+}$ mice (Figure 3A-1). Quantitative analysis showed that the most significant decrease in the number of spiral ganglion cells was found in the Gata $^{\mathrm{G} /+}::$ Gata $^{\mathrm{Z} /+}$ mice at week 20 (Figure 3B). Gata $3^{\mathrm{Z} /+}$ single heterozygous mutants showed modestly decreased numbers of spiral ganglion cells at 20 weeks of age (Figure 3A-i,3B). Despite the pronounced loss in the number of inner ear neurons, overall cochlear architecture was maintained in each genotype of mutant mice at 10 weeks and 20 weeks of age (Figure 3A-a,d,g,j and data not shown).

\subsection{Increased ABR threshold in Gata $^{\mathrm{G} /+}::$ Gata $^{\mathrm{Z} /+}$ compound mutant mice}

Given the significant decrease in the spiral ganglion cell population in the compound Gata mutants, we next subjected adult Gata2 $^{\mathrm{G} /+}::$ Gata3 $^{\mathrm{Z} /+}$ mice to functional hearing tests by click-evoked ABR (auditory brainstem response) at 10 and 20 weeks of age (Figure 3C). Interestingly, we found that the ABR threshold was significantly increased in the 10-week-old Gata2 $^{\mathrm{G} /+}::$ Gata $^{\mathrm{Z} /+}$ mice in comparison with age-matched wild-type mice $(80 \pm 7 \mathrm{~dB}$ vs. $38 \pm 5 \mathrm{~dB}$, respectively) (compare black and white bars in Figure 3C). 

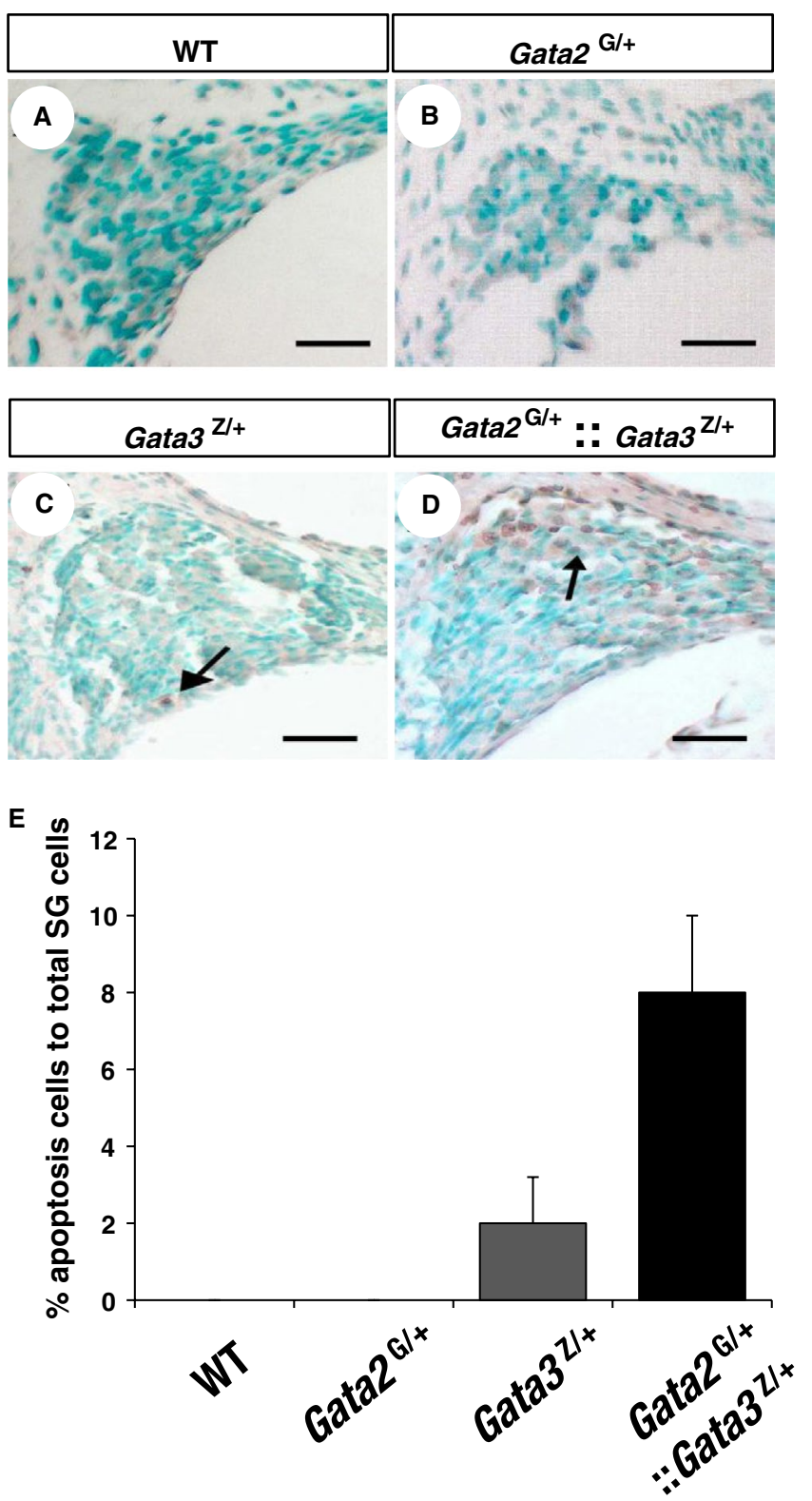

F I G URE 4 Enhanced apoptosis in the spiral ganglion of Gata2 $^{\mathrm{G} /+}::$ Gata $^{\mathrm{z} /+}$ mice. A number of TUNEL-positive cells were found in the spiral ganglion of $\operatorname{Gata2}^{\mathrm{G} /+}:: \operatorname{Gata}^{\mathrm{z} /+}$ mice (D). In contrast, no TUNEL-positive cells were detected in the spiral ganglia of wild-type or Gata2 ${ }^{\mathrm{G} /+}$ mice (A and B). Gata3 ${ }^{\mathrm{z} /+}$ had a modest increase in apoptotic cells in the spiral ganglion (C). Scale bars: $10 \mu \mathrm{m}$. (E) Percentage of TUNEL-positive cells among the total spiral ganglion cells enumerated in five sections of each genotype of mice. Data represent mean $\pm S D$

In comparison, Gata2 $2^{\mathrm{G} /+}$ or Gata3 $^{\mathrm{Z} /+}$ heterozygous mutant mice showed normal ABR thresholds at the 10 weeks of age (Figure 3C). Hearing impairment in the Gata $2^{\mathrm{G} /+}::$ Gata $^{\mathrm{Z} /+}$ mice became progressively exaggerated, as their $\mathrm{ABR}$ threshold further increased by 20 weeks of age (Figure 3C). Heterozygous $\mathrm{Gata} 3^{\mathrm{Z} /+}$ mice also showed a slight increase in the ABR threshold $(70 \pm 10 \mathrm{~dB})$ by 20 weeks of age, whereas Gata $^{\mathrm{G} /+}$ mutant animals remained unaffected. Thus, these results indicate that the simultaneous haploid deficiency in both Gata2 and Gata3 synergistically or additively diminishes hearing ability.

\subsection{Increased apoptosis in the spiral ganglion of Gata $^{\mathrm{G} /+}::$ Gata $^{\mathrm{Z} /+}$ mice}

To address cellular mechanisms underlying the decreased number of spiral ganglion cells in the $\operatorname{Gata2}^{\mathrm{G} /+}::$ Gata $^{\mathrm{Z} /+}$ mice, axial sections of cochlea were subjected to TUNEL analysis before degeneration at neonatal stage. As anticipated, TUNEL-positive cells were found in the spiral ganglion of the Gata $^{\mathrm{G} /+}::$ Gata $^{\mathrm{Z} /+}$ mice (Figure 4D). In contrast, no TUNEL-positive cells were detected in the spiral ganglia of wild-type and Gata2 $^{\mathrm{G} /+}$ littermates (Figure 4A,B). Quantification showed a statistically significant increase of TUNEL-positive cells in the Gata2 $^{\mathrm{G} /+}:$ :Gata3 ${ }^{\mathrm{Z} /+}$ compound mutant mice (Figure 4E). Gata $3^{\mathrm{Z} /+}$ mice also showed a smaller increase in apoptosis, which is in agreement with the modest decrease in spiral ganglion cells at 20 weeks of age (Figure 4C,E). These results suggest that the enhanced apoptosis of spiral ganglion cells led to the loss of cellularity and the subsequent hearing impairment in $\operatorname{Gata}^{\mathrm{G} /+}:: \operatorname{Gata}^{\mathrm{Z} /+}$ mice.

\section{5 $\mid$ TrkC expression is markedly reduced in the Gata $^{\mathrm{G} /+}:$ :Gata $^{\mathrm{Z} /+}$ neonates}

Neurotrophin signaling by neurotrophin-3 (NT3) through the TrkC receptor and brain-derived neurotrophic factor (BDNF) via the TrkB receptor play a role for the development and maintenance of spiral ganglion cells (Fritzsch, Tessarollo, Coppola, \& Reichardt, 2004). Expression of TrkB and TrkC in the inner ear spiral ganglion cells depends on NeuroD, a basic helix-loop-helix (bHLH) transcription factor, and thus, NeuroD-deficient mice show a severe reduction of spiral ganglion cells (Kim et al., 2001). Considering these observations, we addressed the expression profile of these inner ear-affiliated genes to probe possible molecular mechanisms underlying spiral ganglion cell degeneration in the Gata $^{\mathrm{G} /+}::$ Gata $^{\mathrm{Z} /+}$ mice. To this end, we first examined mRNA expression of these genes after dissecting the spiral ganglion region of cochlea. We found that expression of TrkC was most significantly diminished in the Gata $^{\mathrm{G} /+}::$ Gata $^{\mathrm{Z} /+}$ mice compared to the wild-type mice (Figure $5 \mathrm{~A}$ ), whereas that of TrkB appeared to increase, but without statistical significance (Figure 5A). The expression of the neurotrophin genes, Bdnf and NT3, was slightly decreased but again without statistical significance, and NeuroD abundance was unaffected (Figure 5A).

Given the decrease in TrkC expression, we next conducted immunohistochemical analysis for TrkC protein expression. We found that TrkC immunoreactivity was dramatically 
F I G URE 5 mRNA expression of neurotrophin signaling-related genes. (A) TrkC expression is markedly reduced in the Gata2 $^{G /+}::$ Gata $^{Z /+}$ compound mutant mice compared to wild-type control mice. TrkB tended to be higher in the Gata2 $^{G /+}:$ :Gata3 ${ }^{\mathrm{Z} /+}$ mice, albeit below statistical significance. Bdnf and NT3 levels were not significantly changed, and NeuroD was also unaffected. The statistical significance of differences is indicated (**p $<0.01$; Student's $t$ test). (B) TrkC immunoreactivity was markedly reduced in the spiral ganglia of the Gata $^{G /+}::$ Gata $^{Z /+}$ mice (right), whereas wild-type mice abundantly expressed TrkC (left). Scale bars: $20 \mu \mathrm{m}$
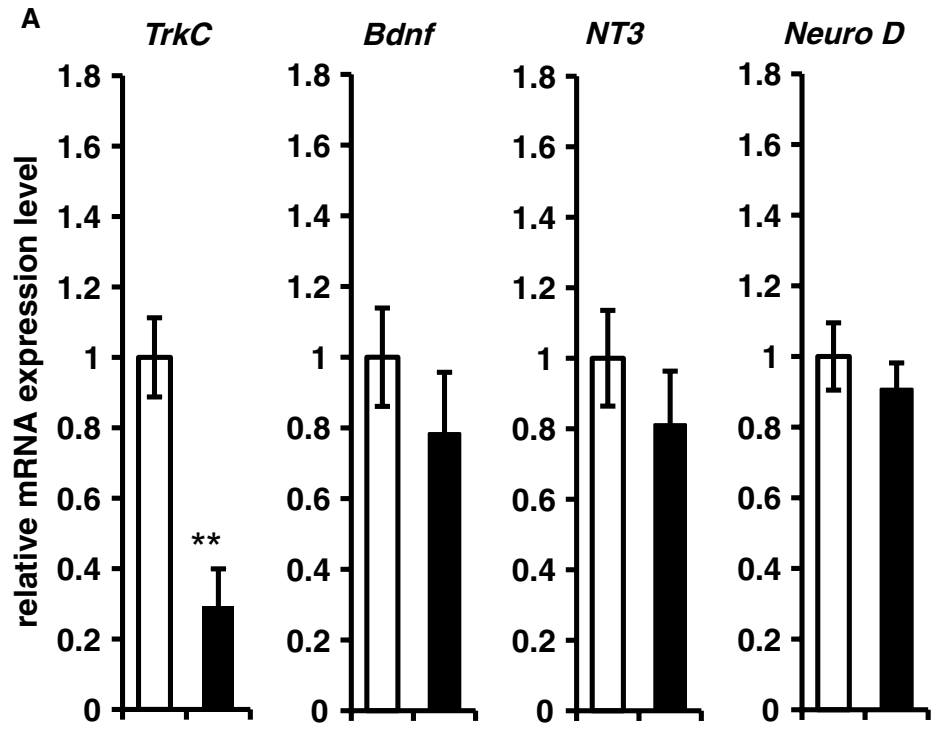

TrkB

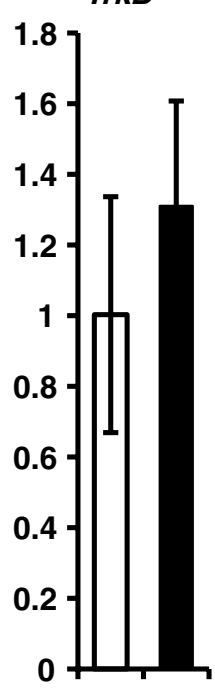

$\square W T \quad \square$ Gata2 $^{\mathrm{G} /+}::$ Gata3 $^{\mathrm{Z} /+}$

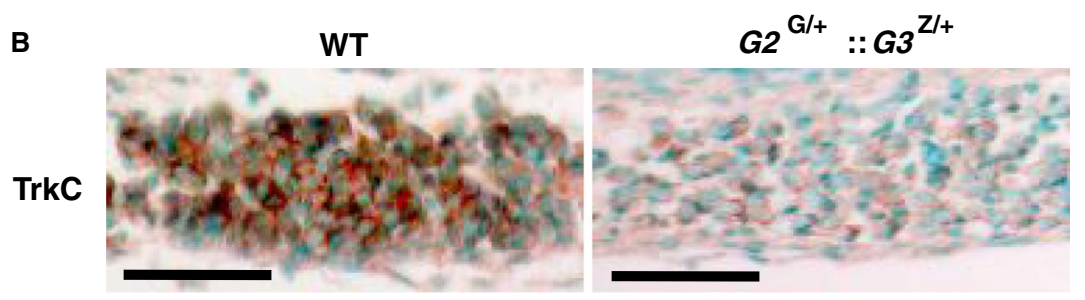

diminished in the spiral ganglion cells of Gata $^{\mathrm{G} /+}::$ Gata $^{\mathrm{Z} /+}$ mice, whereas wild-type mice abundantly expressed TrkC protein in the spiral ganglion cells (Figure 5B). These results suggest that simultaneous heterozygous deletion of Gata2 and Gata 3 led to the observed significant reduction of TrkC mRNA and protein in cochlear spiral ganglion cells. We suggest that the decreased level of TrkC expression may account for the enhanced degeneration of spiral ganglion cells.

\section{6 | GATA2 is required for maintenance of spiral ganglion cells}

The early embryonic lethal anemia of GATA2-deficient mice obscures any developmental functions of GATA2 at later stages (Suzuki et al., 2006; Tsai et al., 1994). To overcome this difficulty, we have previously generated transgenic mouse lines carrying a 271-kb Gata2 yeast artificial chromosome (YAC) that contains the entire Gata2 structural gene plus extended regulatory sequences which direct Gata2 expression in the hematopoietic system $\left(\mathrm{Tg}^{\mathrm{G} 2 \mathrm{YAC}}\right.$ ) (Zhou et al., 1998). We showed that $\mathrm{Tg}^{\mathrm{G} 2 \mathrm{YAC}}$ mice, when bred into the Gata2 null mutant background, rescued the embryonic lethality and allowed them to survive until weaning (Zhou et al., 1998). However, even this $271 \mathrm{~kb}$ YAC lacks regulatory sequences required for otic vesicle-specific Gata2 expression (Zhou et al., 1998). We thus addressed whether the $\mathrm{Tg}^{\mathrm{G} 2 \mathrm{YAC}}$-rescued Gata2 null-deficient neonates $\left(\right.$ Gata2 $^{\mathrm{G} / \mathrm{G}}$ ::
$\mathrm{Tg}^{\mathrm{G} 2 \mathrm{YAC}}$ ) have any developmental defects in the inner ear at the neonatal stage. We found that Gata2 $^{\mathrm{G} / \mathrm{G}}:: \mathrm{Tg}^{\mathrm{G} 2 \mathrm{YAC}}$ neonates suffered from a significant decrease in spiral ganglion cell numbers in comparison with the Gata2 $2^{\mathrm{G} /+}$ control littermates (Figure 6b,c,e,f). Quantification confirmed the statistically significant decrease of spiral ganglion cells in the Gata2 $^{\mathrm{G} / \mathrm{G}}:: \mathrm{Tg}^{\mathrm{G} 2 \mathrm{YAC}}$ mice in comparison with the Gata2 $^{\mathrm{G} /+}$ control (Figure 6G). The GFP expression pattern in the dissected cochlea of Gata2 $^{\mathrm{G} / \mathrm{G}}:: \mathrm{Tg}^{\mathrm{G} 2 \mathrm{YAC}}$ mice was maintained in comparison with the Gata2 ${ }^{\mathrm{G} /+}$ control cochlea, excluding architectural damage (Figure 6A,D). Hair cells of the organ of Corti in the Gata2 ${ }^{\mathrm{G} / \mathrm{G}}:: \mathrm{Tg}^{\mathrm{G} 2 \mathrm{YAC}}$ mice were hardly affected (data not shown). These results indicate that GATA2 activity is essential for the development and maintenance of spiral ganglion cells.

\section{7 | Inner ear-specific conditional Gata2- deficient mice have hearing loss}

Gata2 $^{\mathrm{G} / \mathrm{G}}:: \mathrm{Tg}^{\mathrm{G} 2 \mathrm{YAC}}$ mice succumb to urinary tract anomalies around weaning (Zhou et al., 1998), because the 271-kb Gata2 YAC lacks urogenital primordia-specific regulatory sequences located far 3' to the Gata2 structural gene beyond the YAC boundaries (Khandekar et al., 2004). Thus, to investigate the consequences of inner ear-specific Gata2 loss of function at the adult stage, we used a Gata2-floxed allele $\left(\operatorname{Gata2}^{\mathrm{f}}\right)$. For inner ear-specific Gata2 deletion, we crossed a newly developed Cre 


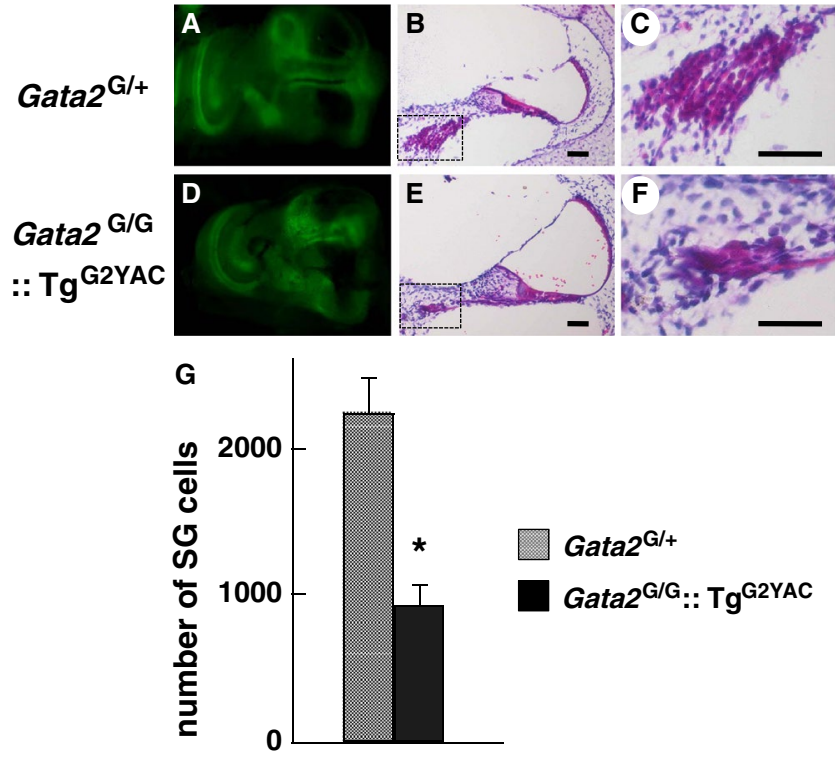

F I G U RE 6 Tg ${ }^{\text {G2YAC }}$-rescued Gata2 null-deficient neonates showed diminished numbers of spiral ganglion cells. No gross abnormality was found in the GFP expression pattern in the cochlea of Gata2 $^{\mathrm{G} / \mathrm{G}}:: \mathrm{Tg}^{\mathrm{G} 2 \mathrm{YAC}}$ mice in comparison with the Gata2 ${ }^{\mathrm{G} /+}$ cochlea (compare A and D). Gata $2^{\mathrm{G} / \mathrm{G}}:: \mathrm{Tg}^{\mathrm{G} 2 \mathrm{YAC}}$ mice showed a significant reduction of spiral ganglion cells in comparison with the Gata2 $^{\mathrm{G} /+}$ control mice by HE-staining comparison (B, C E and F). Scale bars represent $10 \mu \mathrm{m}$. (G) Number of the spiral ganglion cells in the Gata2 $^{\mathrm{G} / \mathrm{G}}:: \mathrm{Tg}^{\mathrm{G} 2 \mathrm{YAC}}$ mice was statistically significantly lower than that of the Gata2 $^{\mathrm{G} /+}$ control mice. More than five mice of each genotype were subjected to the analysis

deleter strain of mice ( $\left.\mathrm{Tg}^{\mathrm{OVE}-\mathrm{Cre}}\right)$ in which Cre recombinase is expressed in the cochlea under the regulation of the otic vesicle-specific enhancer of the mouse Gata3 gene (Moriguchi et al., 2018). We confirmed that the OVE-Cre mice labeled the spiral ganglion cells and the organ of Corti, when crossed with ROSA26-floxed-LacZ (R26R) reporter mice (Figure 7a). The Gata2 $^{\mathrm{f} / \mathrm{f}}:: \mathrm{Tg}^{\mathrm{OVE}-\mathrm{Cre}}$ (G2CKO) mice grew to adulthood with grossly normal appearance and at the expected Mendelian frequency (Table 1). Upon histological analysis, we found that the G2CKO mice showed decreased spiral ganglion cell numbers compared with age-matched control mice at 20 weeks of age (compare Figure 7B,C). Quantification of G2CKO and control mice confirmed a statistically significant decrease in spiral ganglion cells in the G2CKO mice (Figure 7D). Meanwhile, hair cells in the organ of Corti were maintained in the G2CKO mice, indicating that GATA2 is dispensable for the hair cell development (compare Figure 7E,F). Given these observations, we subjected the G2CKO to ABR analysis evoked by pure-tone bursts $(4,8$ or $16 \mathrm{kHz})$. Consistent with the decreased number of spiral ganglion cells, the G2CKO mice showed diminished hearing (Figure 7G). We next examined mRNA expression profile after dissecting the spiral ganglion region of the G2CKO mice. We found that Gata2 mRNA was decreased to $24.9 \%$ in the G2CKO mice compared to that in the wild-type control mice (Figure $7 \mathrm{H}$ ), indicating that the Gata2-floxed allele was deleted in the cochlear tissues. Notably, TrkC expression was diminished in the G2CKO mice compared to the wild-type mice (Figure $7 \mathrm{H}$ ), suggesting that TrkC expression is under the regulatory influence of GATA2 in the spiral ganglion. We also found that GATA3 mRNA expression level was rarely affected in the G2CKO mice (Figure $7 \mathrm{H}$ ), implying that GATA2 might be dispensable for GATA3 expression in the spiral ganglion cells. These results clearly indicate that GATA2 plays a functional role in the maintenance of spiral ganglion cells and hearing ability.

\section{3 | DISCUSSION}

The mammalian inner ear contains sophisticated mechanosensory elements and a series of highly specialized neuronal connections that have evolved for the transduction of mechanical energy to electrical impulses in the cochlear and vestibular nerves. In the auditory system, GATA3 has been recognized to play a role during developmental stages as well as in the adult inner ear, whereas insight into possible physiological functions and expression of GATA2 particularly in the definitive inner ear has not been defined. We and other groups showed that GATA2 expression shows a similar pattern to that of GATA3 in the early embryonic period (Lillevali et al., 2004). Subsequently in the postnatal stage, we found that GATA2 and GATA3 are both highly co-expressed in cochlear spiral ganglion cells. In agreement with this overlapping expression pattern, Gata2 ${ }^{\mathrm{G} /+}::$ Gata $^{\mathrm{Z} /+}$ compound heterozygous mutant mice showed more severely diminished spiral ganglion cell number than did either Gata2 or Gata3 single heterozygous mutant. Spiral ganglion neurons are responsible for the precise connections between hair cells and target neurons in the auditory brainstem (Rubel \& Fritzsch, 2002). Consequently, Gata ${ }^{\mathrm{G} /+}::$ Gata $^{\mathrm{Z} /+}$ compound heterozygous mutants showed more severe hearing loss than either the Gata $^{\mathrm{Z} /+}$ or Gata2 $2^{\mathrm{G} /+}$ heterozygous deficient mice. These results taken together indicate that GATA2 and GATA3 function at least partially redundantly in the maintenance of spiral ganglion cells and thus that the gene dosage of Gata2 and Gata3 is crucial for the survival of spiral ganglion cells and the maintenance of auditory circuitry.

Signaling by NT3 through the TrkC receptor or BDNF via the TrkB receptor supports the inner ear sensory neurons and regulates development of the acoustic neural circuit (Fritzsch et al., 2004). From early developmental stages into adulthood, NT3 and Bdnf are both expressed in the hair cells in the organ of Corti, whereas their respective receptors, that is, TrkB and TrkC, are expressed in the developing spiral ganglion cells (Fritzsch et al., 2004). Consistent with this expression pattern, development of the spiral ganglion cells critically depends on neurotrophin signaling through the Trk receptors. It has been 
OVE-Cre::R26R
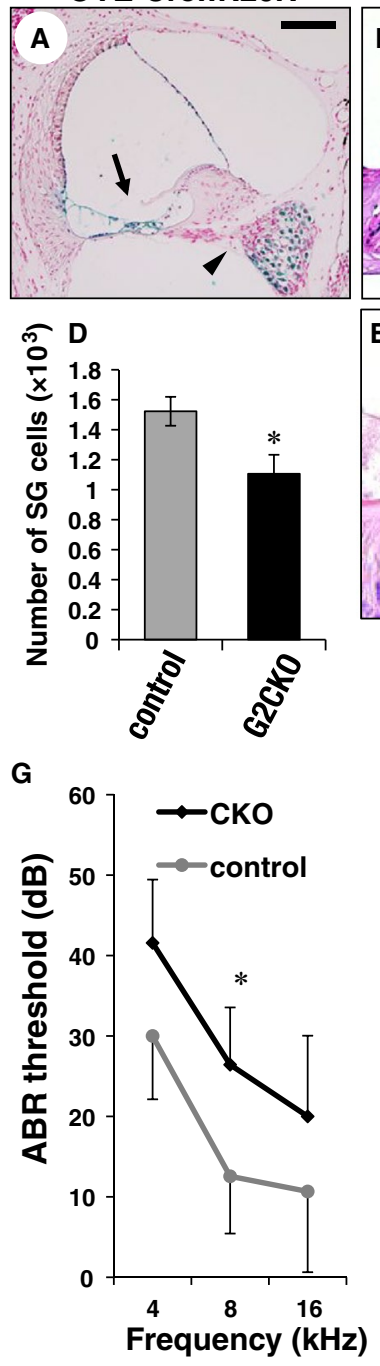

Control
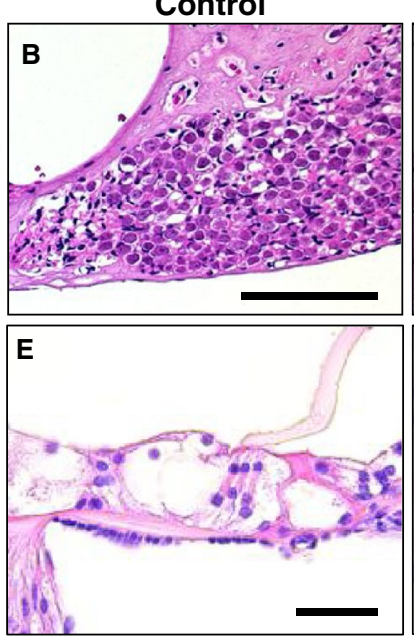

H

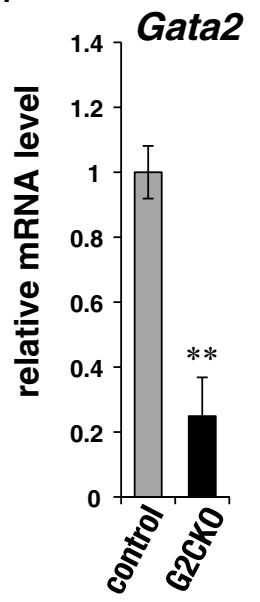

G2CKO

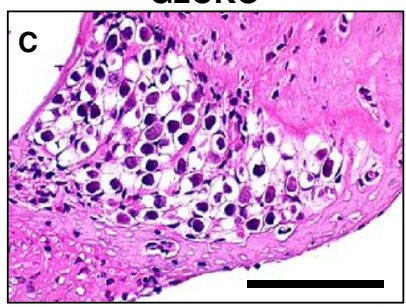

$F$
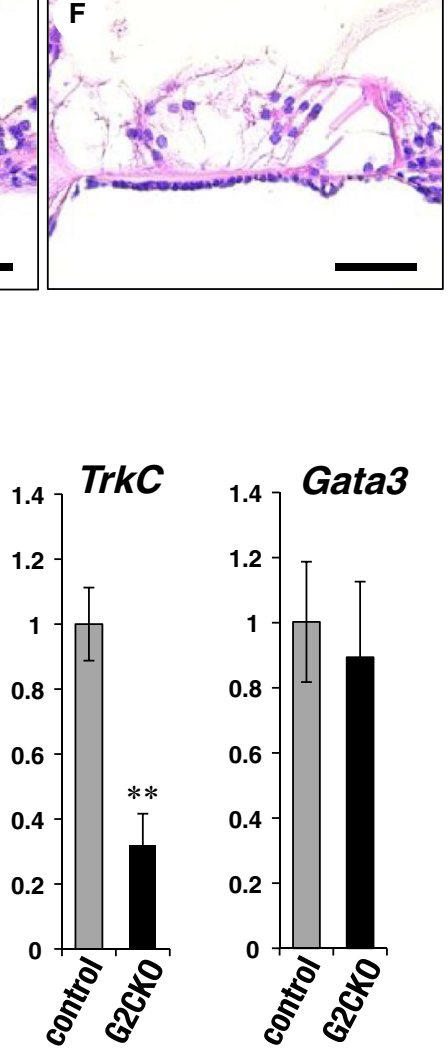

F I G U R E 7 Hearing loss in the inner ear-specific Gata2-deficient (G2CKO) mice. (A) Tg ${ }^{\text {OVE-Cre }}$ mice crossed with ROSA26-floxed-LacZ (R26R) reporter mice showed lacZ expression in the spiral ganglion cells (arrowhead) and organ of Corti (arrow). (B and C) Gata2 ${ }^{\mathrm{f} / \mathrm{f}}: \mathrm{Tg}^{\mathrm{OVE}-\mathrm{Cre}}$ (G2CKO) mice showed diminished spiral ganglion cell numbers at 20 weeks of age in comparison with age-matched wild-type control mice. (D) Quantification of the spiral ganglion cell number confirmed a statistically significant decrease in the G2CKO mice $(n=10)$ compared with controls $(n=14)$. (E and F) The hair cell population in the organ of Corti in the G2CKO mice (F) was comparable to that in the control (E). (G) Pure-tone burst $(4,8$ or $16 \mathrm{kHz}$ )-evoked ABR thresholds in mutant (CKO) or wild-type (control) mice at 20 weeks of age. The ABR thresholds of G2CKO mice were significantly more elevated than those in the age-matched wild-type mice. (H) Gata2 mRNA is reduced to $24.9 \%$ in the G2CKO mice compared to that in the wild-type control mice. Similarly, TrkC expression is reduced in the G2CKO mice. GATA3 mRNA expression level is not significantly different between the G2CKO and control mice. The statistical significance of differences is indicated $(* p<0.05$, $* * p<0.01$; Student's $t$ test). The data represent the mean $\pm S D(n=6-8)$. Scale bars: (A)-(C), $200 \mu \mathrm{m}$; (E)-(F), $50 \mu \mathrm{m}$

shown that mice deficient for NT3 or TrkC lose the vast majority of spiral ganglion cells in the cochlea (Fritzsch, Silos Santiago, Bianchi, \& Farinas, 1997). In mice lacking either

TA B L E 1 Genotyping distribution of progeny from intercrosses between Gata2 $^{\mathrm{f} /+}:: \mathrm{Tg}^{\mathrm{OVE}-C r e}$ and Gata2 $^{\mathrm{f} /+}$

\begin{tabular}{lllllllll} 
& $\mathbf{f} / \mathbf{f}$ & & & $\mathbf{f} /+$ & & & $+/+$ & \\
\cline { 2 - 3 } Genotype & $\mathbf{T g}^{-}$ & $\mathbf{T g}^{+}$ & & $\mathbf{T g}^{-}$ & $\mathbf{T g}^{+}$ & & $\mathbf{T g}^{-}$ & $\mathbf{T g}^{+}$ \\
4 weeks & 12 & 11 & & 18 & 21 & & 10 & 9 \\
\hline
\end{tabular}

Abbreviations: +/+, Gata2 $2^{+/+} ; \mathrm{f} /+$, Gata2 $^{\mathrm{f} / /+} ; \mathrm{f} / \mathrm{f}$, Gata2 $^{\mathrm{f} / \mathrm{f}} ; \mathrm{Tg}, \mathrm{Tg}^{\text {OVE-Cre }}$.
Bdnf or TrkB, the population of spiral ganglion neurons is reduced (Schimmang et al., 2003). In the present study, we showed that TrkC expression was significantly diminished in the spiral ganglia of Gata2 $^{\mathrm{G} /+}::$ Gata $^{\mathrm{Z} /+}$ as well as G2CKO mice in comparison with the wild-type controls, which likely accounts for the loss of spiral ganglion cells in these mutant mice. Notably, TrkB expression tended to be higher in the Gata $^{G /+}:: G a t a 3^{Z /+}$ mice, albeit below statistical significance. TrkB and TrkC are closely related proteins, which have been reported to redundantly function for neuronal cell survival in the brain (Minichiello \& Klein, 1996). Thus, the 
increase of TrkB in the Gata2 $^{\mathrm{G} /+}::$ Gata $^{\mathrm{Z} /+}$ compound mutant mice might partially compensate for the decrease of $\mathrm{TrkC}$ in the spiral ganglion cells. Collectively, the data suggest that TrkC expression could be under either the direct or indirect downstream regulatory influence of GATA2 and GATA3 in the inner ear. In support of this speculation, multiple peaks of GATA2 and GATA3 binding can be detected in nucleotide sequences flanking the TrkC locus in neuroblastoma cell lines (data not shown; UCSF Genome browser. https://genome. ucsc.edu/), and thus, we are currently investigating the regulatory activity of these candidate TrkC enhancers.

There have been a series of reports describing regulatory relationships between Gata2 and Gata3 in the nervous system. In early embryonic neural development, GATA2 expression precedes that of GATA3, and GATA2 is necessary for GATA3 induction in the chick and mouse central nervous system (Nardelli, Thiesson, Fujiwara, Tsai, \& Orkin, 1999; Nozawa et al., 2009; Pata et al., 1999). These reports indicate that GATA2 likely functions upstream of GATA3 in the developing central nervous system. In the auditory system, GATA3 governs the developmental program for inner ear morphogenesis. Gata3 deficiency leads to an early developmental arrest of the otic vesicle, which is accompanied by decreased GATA2 expression (Duncan et al., 2011; Karis et al., 2001; Lillevali et al., 2004). In contrast, virtually normal otic vesicle formation occurs in the Gata2 null mutant embryos before succumbing to hematopoietic deficient lethality at e10.5, in which GATA3 expression sustains (Lillevali et al., 2004). Thus, these data suggest that GATA3 may function hierarchically upstream of GATA2 in early inner ear development.

In the adult inner ear, as we showed here, GATA3 expression domain in the organ of Corti was broader than that of GATA2. The loss of GATA3 elicits a more prominent defect than the loss of GATA2 for the maintenance of spiral ganglion cells. Thus, GATA3 appears to play a dominant role and possibly acts upstream of GATA2 in the adult inner ear. Consistent with this notion, GATA3 mRNA expression was rarely affected in the G2CKO mice, indicating that GATA2 is dispensable for the GATA3 expression in the inner ear. These results indicate that hierarchical relationship between Gata2 and Gata3 in the auditory system is different, and perhaps reversed, from that observed in the developing central nervous system. The complex regulatory relationship between Gata 2 and Gata 3 expression probably depends on the context in which the two factors are found during development and appear to differ from organ to organ.

It has been reported that Gata2 null-deficient embryos rarely show phenotypic abnormalities early in inner ear development before lethality is found by around e10.5. However, the midgestational lethality of the Gata2 null mutant embryos has obscured GATA2 function for the subsequent development and maintenance of the inner ear tissues in the later embryonic and adult stages. An inner ear-specific
Gata2 conditional deletion study using a Foxg1-Cre deleter mouse strain (Haugas et al., 2010; Hebert \& McConnell, 2000) has been investigated previously. However, Foxg1-Cre mice induced an unexpectedly broad recombination pattern, and thus, using that less specific Cre deleter mouse model led to global edema and local hemorrhages by e18.5 (Haugas et al., 2010). Thus, precise GATA2 function in the inner ear during postnatal periods could not be clarified. In this regard, our YAC-rescued Gata2 null-deficient mice survived perinatally and showed a decrease in the number of spiral ganglion cells as a consequence of Gata2 loss. Furthermore, the Gata2 conditional mutants crossed with the newly developed OVECre mice survived to adulthood and had an increased ABR threshold. Both of these new mouse models have clearly been useful in elucidating GATA2 function for inner ear development and postnatal hearing ability and to clarify the molecular aetiology underlying the sensorineural deafness due to GATA2 haploinsufficiency.

Hearing loss is the most common sensory disorder in humans, as congenital hearing loss occurs in approximately 1 affected child out of every 650 newborns (Mehl \& Thomson, 2002). A series of studies have described that a progressive loss of the cochlear spiral ganglion cells is very frequently associated with a number of syndromic hearing loss phenotypes in human (Shibata, Budenz, Bowling, Pfingst, \& Raphael, 2011; Wang \& Puel, 2018). In this context, it would be of significant interest to ask whether the hearing loss in either GATA2 or GATA3 haploinsufficient humans is associated with degenerative loss of spiral ganglion cells, as we showed here in mouse models. Further investigation into the physiological function of GATA2 and GATA3 in the auditory system should provide additional insight into the etiological basis underlying sensorineural deafness and may lead to possible therapeutic approaches for this common sensory disorder.

\section{1 | Experimental procedures}

\subsection{1 | Germ line mutant mice}

The Gata3 nlacZ knock-in (Gata3 $\left.{ }^{Z}\right)$ null mutant, Gata2green fluorescent protein (GFP) knock-in $\left(\right.$ Gata2 $\left.^{\mathrm{G}}\right)$ and Gata2-floxed alleles $\left(\right.$ Gata2 $\left.^{\mathrm{f}}\right)$ have been described previously (van Doornick et al., 1999; Hendriks et al., 1999; Lim et al., 2012; Minegishi et al., 2003; Suzuki et al., 2006). The Gata2 d16YAC transgenic line ( Tg $^{\text {G2YAC }}$ ), which contains $250 \mathrm{~kb}$ of genetic information (from approximately -150 to $+80 \mathrm{~kb}$ of the Gata2 locus), was described previously (Zhou et al., 1998). The generation and characterization of the Gata3 otic vesicle-specific enhancer (OVE)-driven Cre transgenic mice ( $\mathrm{Tg}^{\mathrm{OVE}-\mathrm{Cre}}$ ) have been reported recently (Moriguchi et al., 2018). All mice were handled according to the regulations of the standards for use of laboratory animals at Tohoku Medical and Pharmaceutical University, Tohoku University 
TA B L E 2 Sequence of primers used in RT-qPCR

\begin{tabular}{|llll}
\hline Gene & Sense primer & Antisense primer & Assay \\
\hline TrkC & CTGAGTGCTACAATCTAAGCCC & CACACCCCATAGAACTTGACAAT & RT-qPCR \\
\hline Bdnf & TGCAGGGGCATAGACAAAAGG & CTTATGAATCGCCAGCCAATTCTC & RT-qPCR \\
\hline$N T 3$ & GGAGTTTGCCGGAAGACTCTC & GGGTGCTCTGGTAATTTTCCTTA & RT-qPCR \\
\hline NeuroD & ACTACCTGTGACCTTTCCCA & GAAGTGCTAAGGCAACGCAA & RT-qPCR \\
\hline TrkB & AAGGACTTTCATCGGGAAGCTG & TCGCCCTCCACACAGACAC & RT-qPCR \\
\hline Gata2 & ACCTGTGCAATGCCTGTGGG & TTGCACAACAGGTGCCCGCT & RT-qPCR \\
\hline Gata3 & GGTGGACGTACTTTTTAACATCGA & CCCTGACGGAGTTTCCGTAG & RT-qPCR \\
\hline rRNA & CGGCTACCACATCCAAGGAA & GCTGGAATTACCGCGGCT \\
\hline
\end{tabular}

and the University of Michigan. All animal procedures follow guidelines established for the proper conduct of animal experiments from the Ministry of Education, Culture, Sports, Science and Technology (MEXT) of Japan.

\subsection{2 | Auditory brainstem response (ABR) testing}

Auditory brainstem response testing was conducted basically as previously described (Hoshino et al., 2011). Briefly, wildtype (Wt), Gata2 ${ }^{\mathrm{G} /+}$, Gata3 $^{\mathrm{Z} /+}$, Gata2 ${ }^{\mathrm{G} /+}::$ Gata3 $^{\mathrm{Z} /+}$ compound heterozygous and Gata2 ${ }^{\mathrm{f} / \mathrm{f}}:: \mathrm{Tg}^{\mathrm{OVE}-\mathrm{Cre}}$ mice, ranging from 10 to 20 weeks old, were subjected to ABR tests in a soundproof room under anesthesia with intraperitoneal injection of $\mathrm{Na}^{+}$pentobarbital $(20 \mathrm{mg} / \mathrm{kg}$ ) (Nembutal; Abbott Laboratories). The ABR responses were evoked using bursts of pure tones (4, 8 or $16 \mathrm{kHz}$ ) or click sounds and were recorded with a Synax 1200 system (NEC). The ABR threshold was determined with increment or decrement of sound pressure in $5 \mathrm{~dB}$ steps.

\subsubsection{Histological analysis and cell count}

Adult mice were anesthetized with pentobarbital sodium $(20 \mathrm{mg} / \mathrm{kg}$ ) and were transcardially perfused with cold phosphate-buffered saline (PBS: $0.1 \mathrm{M}, \mathrm{pH}$ 7.4) followed by perfusion with $4 \%$ paraformaldehyde (PFA). Mouse tissues were post-fixed in $4 \%$ paraformaldehyde (PFA) at $4{ }^{\circ} \mathrm{C}$ overnight. Thereafter, the cochleas were decalcified using $8 \%$ EDTA solution and processed for paraffin embedding. Serial paraffin sections $(7 \mu \mathrm{m})$ were stained with $\mathrm{HE}$, and total spiral ganglion neurons in the 1st turn of the cochlea were counted in every fourth section throughout the specimen.

\subsection{4 | Immunohistochemistry, X-gal staining and TUNEL assay}

Gata $^{\mathrm{G} /+}$ embryos (at e10.5, e12.5 and e14.5 dpc) were examined by fluorescence microscopy (Leica Microsystems, Wetzlar, German). Whole-embryo X-gal staining was carried out as described previously (Lakshmanan et al., 1998).
The Gata2 $^{\mathrm{G} /+}::$ Gata3 $^{\mathrm{Z} /+}$ cochleae were dissected from P3 mice, fixed in $4 \%$ PFA and subjected to X-gal staining and immunohistochemistry (IHC) with rabbit anti-GFP antibody (diluted 1:1,000; Molecular Probes). Apoptotic cells were detected by TUNEL (TdT-mediated dUTP nick end labeling) assay on $10-\mu \mathrm{m}$ tissue cryosections according to the manufacturer's instruction (In Situ Apoptosis Detection Kit). Methyl green solution was used for the counterstaining.

\subsection{5 | RT-PCR analysis using central core region of the cochlea}

In order to dissect the presumptive spiral ganglion region, temporal bones of newborn mice were removed quickly and dissected in ice-cold PBS ( $\mathrm{pH}$ 7.4). The spiral ganglion region was dissected from the central core of the cochlea in the temporal bone, which was subsequently subjected to total RNA isolation using ISOGEN (Nippon Gene). The RNA sample was subjected to quantitative RT-PCR (RT-qPCR) as described previously (Hoshino et al., 2011). Primers used for the RT-qPCR analysis are listed in Table 2.

\subsection{6 | Statistical analyses}

All the data are presented as means $\pm S D$. Statistical analyses were carried out using the unpaired Student's $t$ test (twotailed). Any test resulting in a $p$ value of less than 0.05 was considered significant.

\section{ACKNOWLEDGMENTS}

We thank the Microscopy and Imaging Analysis Laboratory for assistance with electron microscopy and the Transgenic Animal Model Core at the University of Michigan. We also thank the Biomedical Research Core of Tohoku University Graduate School of Medicine for technical support. This study was supported by Grant-in-Aid for Scientific Research (B) and on Innovative Areas (grant 16H05147 and grant 18H05041 to T.M.) and the Kobayashi Foundation for Cancer Research (T.M.). 


\section{ORCID}

Takashi Moriguchi (D) https://orcid. org/0000-0002-5341-8932

\section{REFERENCES}

Ainoya, K., Moriguchi, T., Ohmori, S., Souma, T., Takai, J., Morita, M., ... Yamamoto, M. (2012). UG4 enhancer-driven GATA-2 and bone morphogenetic protein 4 complementation remedies the CAKUT phenotype in Gata2 hypomorphic mutant mice. Molecular and Cellular Biology, 32, 2312-2322. https://doi.org/10.1128/ MCB.06699-11

Barald, K. F., \& Kelley, M. W. (2004). From placode to polarization: New tunes in inner ear development. Development, 131, 4119-4130. https://doi.org/10.1242/dev.01339

Craven, S. E., Lim, K. C., Ye, W., Engel, J. D., de Sauvage, F., \& Rosenthal, A. (2004). Gata2 specifies serotonergic neurons downstream of sonic hedgehog. Development, 131, 1165-1173. https:// doi.org/10.1242/dev.01024

Duncan, J. S., Lim, K. C., Engel, J. D., \& Fritzsch, B. (2011). Limited inner ear morphogenesis and neurosensory development are possible in the absence of GATA3. International Journal of Developmental Biology, 55, 297-303. https://doi.org/10.1387/ ijdb.103178jd

Fritzsch, B., Silos Santiago, I., Bianchi, L. M., \& Farinas, I. (1997). The role of neurotrophic factors in regulating the development of inner ear innervation. Trends in Neurosciences, 20, 159-164. https://doi. org/10.1016/S0166-2236(96)01007-7

Fritzsch, B., Tessarollo, L., Coppola, E., \& Reichardt, L. F. (2004). Neurotrophins in the ear: Their roles in sensory neuron survival and fiber guidance. Progress in Brain Research, 146, 265-278. https:// doi.org/10.1016/S0079-6123(03)46017-2

George, K. M., Leonard, M. W., Roth, M. W., Liew, K. W., Kioussis, D., Grosveld, F., \& Engel, J. D. (1994). Embryonic expression and cloning of the murine GATA-3 gene. Development, 120, 2673-2686.

Haugas, M., Lillevli, K., Hakanen, J., \& Salminen, M. (2010). Gata2 is required for the development of inner ear semicircular ducts and the surrounding perilymphatic space. Developmental Dynamics, S239, 2452-2469. https://doi.org/10.1002/dvdy.22373

Hebert, J. M., \& McConnell, S. K. (2000). Targeting of cre to the Foxg1 (BF-1) locus mediates loxP recombination in the telencephalon and other developing head structures. Developmental Biology, 222, 296306. https://doi.org/10.1006/dbio.2000.9732

Hendriks, R. W., Nawijn, M. C., Engel, J. D., van Doorninck, H., Grosveld, F., \& Karis, A. (1999). Expression of the transcription factor GATA3 is required for the development of the earliest T cell progenitors and correlates with stages of cellular proliferation in the thymus. European Journal of Immunology, 29, 1912-1918. https ://doi.org/10.1002/(SICI)1521-4141(199906)29:06<1912:AIDIMMU1912>3.0.CO;2-D

Hoshino, T., Shimizu, R., Ohmori, S., Nagano, M., Pan, X., Ohneda, O., ... Engel, J. D. (2008). Reduced BMP4 abundance in Gata2 hypomorphic mutant mice result in uropathies resembling human CAKUT. Genes to Cells, 13, 159-170. https://doi. org/10.1111/j.1365-2443.2007.01158.x

Hoshino, T., Tabuchi, K., Nishimura, B., Tanaka, S., Nakayama, M., Ishii, T., ... Hara, A. (2011). Protective role of Nrf2 in age-related hearing loss and gentamicin ototoxicity. Biochemical and Biophysical Research Communications, 415, 94-98. https://doi. org/10.1016/j.bbrc.2011.10.019

Karis, A., Pata, I., van Doorninck, J. H., Grosveld, F., de Zeeuw, C. I., de Caprona, D., \& Fritzsch, B. (2001). Transcription factor GATA3 alters pathway selection of olivocochlear neurons and affects morphogenesis of the ear. The Journal of Comparative Neurology, 429, 615-630. https://doi.org/10.1002/1096-9861(20010 122)429:4<615:AID-CNE8>3.0.CO;2-F

Kazenwadel, J., Secker, G. A., Liu, Y. J., Rosenfeld, J. A., Wildin, R. S., Cuellar-Rodriguez, J., ... Harvey, N. L. (2012). Loss-of-function Germline GATA2 mutations in patients with MDS/AML or MonoMAC syndrome and primary lymphedema reveal a key role for GATA2 in the lymphatic vasculature. Blood, 119, 1283-1291. https://doi.org/10.1182/blood-2011-08-374363

Khandekar, M., Brandt, W., Zhou, Y., Dagenais, S., Glover, T. W., Suzuki, N., ... Engel, J. D. (2007). A Gata2 intronic enhancer confers its pan-endothelia-specific regulation. Development, 134, 1703-1712. https://doi.org/10.1242/dev.001297

Khandekar, M., Suzuki, N., Lewton, J., Yamamoto, M., \& Engel, J. D. (2004). Multiple, distant Gata2 enhancers specify temporally and tissue-specific patterning in the developing urogenital system. Molecular and Cellular Biology, 24, 10263-10276. https://doi. org/10.1128/MCB.24.23.10263-10276.2004

Kim, W. Y., Fritzsch, B., Serls, A., Bakel, L. A., Huang, E. J., Reichardt, L. F., ... Lee, J. E. (2001). NeuroD-null mice are deaf due to a severe loss of the inner ear sensory neurons during development. Development, 128, 417-426.

Ko, L. J., \& Engel, J. D. (1993). DNA-binding specificities of the GATA transcription factor family. Molecular and Cellular Biology, 13, 4011-4022. https://doi.org/10.1128/MCB.13.7.4011

Lakshmanan, G., Lieuw, K. H., Grosveld, F., \& Engel, J. D. (1998). Partial rescue of GATA-3 by yeast artificial chromosome transgene. Developmental Biology, 204, 451-463. https://doi.org/10.1006/ dbio.1998.8991

Lakshmanan, G., Lieuw, K. H., Lim, K. C., Gu, Y., Grosveld, F., Engel, J. D., \& Karis, A. (1999). Localization of distant urogenital system-, central nervous system- and endocardium-specific transcriptional regulatory elements in the GATA-3 locus. Molecular and Cellular Biology, 19, 1558-1568. https://doi.org/10.1128/MCB.19.2.1558

Lawoko-Kerali, G., Rivolta, M. N., \& Holley, M. (2002). Expression of the transcription factors GATA3 and Pax2 during development of the mammalian inner ear. The Journal of Comparative Neurology, 442, 378-391. https://doi.org/10.1002/cne.10088

Lieuw, K. W., Li, G., Zhou, Y., Grosveld, F., \& Engel, J. D. (1997). Temporal and spatial control of murine GATA-3 transcription by promotor-proximal regulatory elements. Developmental Biology, 188, 1-16.

Lillevali, K., Matilainen, T., Karis, A., \& Salminen, M. (2004). Partially overlapping expression of Gata2 and Gata3 during inner ear development. Developmental Dynamics, 231, 775-781. https://doi. org/10.1002/dvdy.20185

Lim, K.-C., Hosoya, T., Brandt, W., Ku, C.-J., Hosoya-Ohmura, S., Camper, S. A., ... Engel, J. D. (2012). Conditional Gata2 inactivation results in HSC loss and lymphatic mispatterning. Journal of Clinical Investigation, 122, 3705-3717. https://doi.org/10.1172/JCI61619

Lim, K. C., Lakshmanan, G., Crawford, S. E., Gu, Y., Grosveld, F., \& Engel, J. D. (2000). Gata3 loss leads to embryonic lethality due to noradrenaline deficiency of the sympathetic nervous system. Nature Genetics, 25, 209-212. https://doi.org/10.1038/76080 
Mehl, A. L., \& Thomson, V. (2002). The Colorado newborn hearing screening project, 1992-1999: On the threshold of effective population-based universal newborn hearing screening. Pediatrics, 109, E7. https://doi.org/10.1542/peds.109.1.e7

Minegishi, N., Suzuki, N., Yokomizo, T., Pan, X., Fujimoto, T., Takahashi, S., ... Yamamoto, M. (2003). Expression and domainspecific function of GATA2 during differentiation of the hematopoietic precursor cells in midgestation mouse embryos. Blood, 102, 896-905. https://doi.org/10.1182/blood-2002-12-3809

Minichiello, L., \& Klein, R. (1996). TrkB and TrkC neurotrophin receptors cooperate in promoting survival of hippocampal and cerebellar granule neurons. Genes \& Development, 10, 2849-2858. https://doi. org/10.1101/gad.10.22.2849

Moriguchi, T., Hoshino, T., Rao, A., Yu, L., Takai, J., Uemura, S., ... Engel, J. D. (2018). A Gata3 3' distal otic vesicle enhancer directs inner ear-specific Gata3 expression. Molecular and Cellular Biology, 38, https://doi.org/10.1128/MCB.00302-18

Moriguchi, T., Takako, N., Hamada, M., Maeda, A., Fujioka, Y., Kuroha, T., ... Engel, J. D. (2006). Gata3 participates in a complex transcriptional feedback network to regulate sympathoadrenal differentiation. Development, 133, 3871-3881. https://doi. org/10.1242/dev.02553

Nardelli, J., Thiesson, D., Fujiwara, Y., Tsai, F. Y., \& Orkin, S. H. (1999). Expression and genetic interaction of transcription factors GATA-2 and GATA-3 during development of the mouse central nervous system. Developmental Biology, 210, 305-321. https://doi. org/10.1006/dbio.1999.9278

Nozawa, D., Suzuki, N., Kobayashi-Osaki, M., Pan, X., Engel, J. D., \& Yamamoto, M. (2009). GATA2-dependent and region-specific regulation of Gata2 transcription in the mouse midbrain. Genes to Cells, 14, 569-582. https://doi. org/10.1111/j.1365-2443.2009.01289.x

Ostergaard, P., Simpson, M. A., Connell, F. C., Steward, C. G., Brice, G., Woollard, W. J., ... Mansour, S. (2011). Mutations in GATA2 cause primary lymphedema associated with a predisposition to acute myeloid leukemia (Emberger syndrome). Nature Genetics, 2011(43), 929-931. https://doi.org/10.1038/ng.923

Pandolfi, P. P., Roth, M. E., Karis, A., Leonard, M. W., Dzierzak, E., Grosveld, F. G., ... Lindenbaum, M. H. (1995). Targeted disruption of the GATA3 gene causes severe abnormalities in the nervous system and fetal liver haematopoiesis. Nature Genetics, 11, 40-44. https://doi.org/10.1038/ng0995-40

Pata, I., Studer, M., van Doorninck, J. H., Briscoe, J., Kuuse, S., Engel, J. D., ... Karis, A. (1999). The transcription factor GATA3 is a downstream effector of Hoxb1 specification in rhombomere 4. Development, 126, 5523-5531.

Rubel, E. W., \& Fritzsch, B. (2002). Auditory system development: Primary auditory neurons and their targets. Annual Review of Neuroscience, 25, 51-101. https://doi.org/10.1146/annur ev.neuro.25.112701.142849

Schimmang, T., Tan, J., Müller, M., Zimmermann, U., Rohbock, K., Köpschall, I., ... Knipper, M. (2003). Lack of Bdnf and TrkB signalling in the postnatal cochlea leads to a spatial reshaping of innervation along the tonotopic axis and hearing loss. Development, 130, 4741-4750. https://doi.org/10.1242/dev.00676

Shibata, S. B., Budenz, C. L., Bowling, S. A., Pfingst, B. E., \& Raphael, Y. (2011). Nerve maintenance and regeneration in the damaged cochlea. Hearing Research, 281, 56-64. https://doi.org/10.1016/j. heares.2011.04.019

Spinner, M. A., Sanchez, L. A., Hsu, A. P., Shaw, P. A., Zerbe, C. S., Calvo, K. R., ... Holland, S. M. (2014). GATA2 deficiency: A protean disorder of hematopoiesis, lymphatics, and immunity. Blood, 123, 809-821. https://doi.org/10.1182/blood-2013-07-515528

Suzuki, N., Ohneda, O., Minegishi, N., Nishikawa, M., Ohta, T., Takahashi, S., ... Yamamoto, M. (2006). Combinatorial Gata2 and Sca1 expression defines hematopoietic stem cells in the bone marrow niche. Proceedings of the National Academy of Sciences of the United States of America, 103, 2202-2207. https://doi.org/10.1073/ pnas.0508928103

Tsai, F.-Y., Keller, G., Kuo, F. C., Weiss, M., Chen, J., Rosenblatt, M., ... Orkin, S. H. (1994). An early haematopoietic defect in mice lacking the transcription factor GATA-2. Nature, 371, 221-226. https:// doi.org/10.1038/371221a0

van der Wees, J., van Looij, M. A. J., de Ruiter, M. M., Elias, H., van der Burg, H., Liem, S.-S., ... van Doorninck, J. H. (2004). Hearing loss following Gata3 haploinsufficiency is caused by cochlear disorder. Neurobiology of Diseases, 16, 169-178. https://doi.org/10.1016/j. nbd.2004.02.004

van Doornick, J. H., Van der Wees, J., Karis, A., Goedknegt, E., Engel, J. D., \& Coesmans, M., ... DeZeeuw, C. I. (1999). Gata3 is involved in the development of serotonergic neurons in the caudal raphe nuclei. Journal of Neuroscience, 19(RC12), 1-8.

Van Esch, H., Groenen, P., Nesbit, M. A., Schuffenhauer, S., Lichtner, P., Vanderlinden, G., ... Devriendt, K. (2000). GATA3 haplo-insufficiency causes human HDR syndrome. Nature, 406, 419-422. https ://doi.org/10.1038/35019088

Wang, J., \& Puel, J. L. (2018). Toward cochlear therapies. Physiological Reviews, 98, 2477-2522. https://doi.org/10.1152/physr ev.00053.2017

Whitfield, T. T. (2015). Development of the inner ear. Current Opinion in Genetics \& Development, 32, 112-118. https://doi.org/10.1016/j. gde.2015.02.006

Yamamoto, M., Ko, L. J., Leonard, M. W., Beug, H., Orkin, S. H., \& Engel, J. D. (1990). Activity and tissue-specific expression of the transcription factor NF-E1 [GATA] multigene family. Genes \& Dev, 4, 1650-1662.

Zhou, Y., Lim, K. C., Onodera, K., Takahashi, S., Ohta, J., Minegishi, N., ... Engel, J. D. (1998). Rescue of the embryonic lethal hematopoietic defect reveals a critical role for GATA2 in urogenital development. EMBO Journal, 17, 6689-6700. https://doi.org/10.1093/ emboj/17.22.6689

Zhou, Y., Yamamoto, M., \& Engel, J. D. (2000). GATA2 is required for the generation of V2 interneurons. Development, 127, 3829-3838.

How to cite this article: Hoshino T, Terunuma T, Takai $\mathrm{J}$, et al. Spiral ganglion cell degeneration-induced deafness as a consequence of reduced GATA factor activity. Genes Cells. 2019;24:534-545. https://doi. org/10.1111/gtc. 12705 